\title{
Pancreatoduodenectomy En Bloc With Vascular Resections in Borderline Resectable Pancreatic Cancer
}

\author{
NICOLAE BACALBASA ${ }^{1,2,3^{*}}$, IRINA BALESCU ${ }^{4}$, SIMONA DIMA $^{3}$, ADINA CROITORU $^{3,5^{*}}$, \\ VLADISLAV BRASOVEANU ${ }^{3,5}$, MIHAELA VILCU ${ }^{1,2}$ and IULIAN BREZEAN ${ }^{1,2}$ \\ 1 "Carol Davila" University of Medicine and Pharmacy, Bucharest, Romania; \\ 2"I. Cantacuzino" Clinical Hospital, Bucharest, Romania; \\ 3 "Fundeni" Clinical Institute - Center of Excellence in Translational Medicine, Bucharest, Romania; \\ 4"Ponderas" Academic Hospital, Bucharest, Romania; \\ 5 "Titu Maiorescu” University, Bucharest, Romania
}

\begin{abstract}
Background/Aim: Pancreatic cancer remains asymptomatic for a long period of time, being frequently diagnosed when vascular invasion is already present. Such cases are widely known as borderline lesions. The aim of this study was to identify the effectiveness of vascular resection in this subgroup of patients. Patients and Methods: Fifteen such cases were submitted to surgery with curative intent. Results: Eight cases were diagnosed with borderline resectable lesions with portal vein invasion and were submitted to per primam resection and seven cases were initially diagnosed with arterial invasion and had been initially submitted to neoadjuvant chemotherapy followed by resection. In all cases portal vein resection was needed while in other four cases association of superior mesenteric artery resection was performed. Postoperatively, five patients developed complications requiring reoperation, three of whom died at the end of the first postoperative month. The histopathological studies confirmed the completeness of resection in all cases. Conclusion: Vascular resections in pancreatic cancer resections remain demanding procedures, and are reserved for cases in which a radical resection is feasible.
\end{abstract}

Pancreatic cancer remains one of the most aggressive malignancies affecting people worldwide, which is

This article is freely accessible online.

*These Authors contributed equally to this study.

Correspondence to: Irina Balescu, "Ponderas" Academic Hospital, Bucharest, Romania. Tel: +40 724077709, e-mail: irina.balescu@ ponderas-ah.ro

Key Words: Pancreatic cancer, pancreatoduodenectomy, vascular resection. unfortunately associated with poor rates of survival. Data reported so far demonstrate that in the absence of surgery, patients with pancreatic cancer will survive only few months after diagnosis $(1,2)$; however, in cases in which surgery with curative intent is feasible a significant benefit in terms of survival can be achieved, the five-year overall survival being $20-25 \%(2,3)$. Unfortunately, at this moment only 15 $20 \%$ of cases are candidates for upfront surgery when diagnosis is established, and this proportion has been rather constant for decades (2).

Once the benefit of radical surgery was demonstrated, the attention of surgeons focused on increasing the rates of patients who will benefit at a certain moment from surgery with curative intent. In the meantime, improvement of the surgical techniques and of the perioperative management of these patients as well as the experience gained by surgeons after performing complex procedures of hepatobiliary surgery and liver transplantation provided the possibility of adjusting certain gestures of vascular resection in pancreatic surgery. Therefore, more complex procedures have become feasible and otherwise unresectable pancreatic tumors have been submitted to resection with curative intent (4-12).

These types of pancreatic tumors are widely known as borderline resectable pancreatic malignancies; this notion includes both anatomical and oncological factors. The anatomical factors are related to the encasement of venous structures such as the portal vein or the superior mesenteric vein and/or arterial structures such as the celiac trunk, the superior mesenteric artery or the common hepatic artery (1316). The oncological factors are rather related to the positivity of the lymph nodes or to the presence of increased levels of CA 19-9 (beyond a certain threshold). In anatomical borderline resectable cases, although initially it was considered that surgery is not feasible, in the last decades resection has suggested with curative intent. Nowadays, in such cases the therapeutic strategy might consist of per 
primam resection or neoadjuvant chemotherapy followed by resection. The objective of the present study was to present a case series of 15 patients submitted to surgery as first intent treatment or after neoadjuvant chemotherapy.

\section{Patients and Methods}

Between 2013 and 2017, 15 patients with anatomical borderline pancreatic tumors have been submitted to surgery with radical intent. The patients were included in the present study after obtaining the approval of the Ethical Committee (no 44/2018). The local extension of the tumoral process was determined by using objective criteria given by the magnetic resonance imaging and computed tomography; according to these information, anatomical borderline resectable lesions were defined by the following criteria: (a) more than $50 \%$ reduction in the diameter of the venous structures - portal vein alone or in association with superior mesenteric vein or short length of occlusion of a venous segment, suitable for resection and reconstruction, (b) less than 180 degrees encasement of the superior mesenteric artery, (c) abutment of the celiac trunk or of the common hepatic artery but in the absence of the extension at the level of the celiac axis or common hepatic artery bifurcation (17). Criteria of initially unresectable pancreatic head cancer were related to the presence of a greater than 180 degrees encasement of the superior mesenteric artery or celiac trunk. In these cases, neoadjuvant chemotherapy for decreasing the tumoral volume followed by surgery was the option of choice.

Postoperative complications were classified according to the Clavien-Dindo system (18) and to the International Study Group of Pancreatic Surgery (19)

\section{Results}

Among the 15 cases there were eight cases submitted to per primam resection while in the other seven cases neoadjuvant chemotherapy consisting of 5-fluorouracil, leucovorin, irinotecan and oxaliplatin (FOLFIRINOX) was administrated. Decision to submit the patient to per primam surgical procedure or to neoadjuvant chemotherapy followed by resection was taken after studying the imaging details; patients presenting limited portal vein invasion were submitted to surgery as the first therapeutic intent, while patients presenting both venous and arterial invasion were submitted to neoadjuvant chemotherapy. However, among cases in which arterial resection had not been seen during preoperative examination, there were two cases in which intraoperatively a limited degree of superior mesenteric artery invasion was encountered. In both cases resection with curative intent was performed, the continuity of the superior mesenteric artery being re-established by direct reimplantation at the level of the abdominal aorta. As for the type of pancreatic resection, in the first case a pancreatoduodenectomy was performed; however, the patient developed a pancreatic leak which eroded the arterial reimplantation leading to the development of a fulminant bleeding that led to the death of the patient during the early postoperative period. In consequence, in the other case, in which intraoperative invasion of the superior mesenteric artery was found, we decided to perform a total pancreatectomy followed by superior mesenteric artery reimplantation.

In all cases in which neoadjuvant chemotherapy was administrated re-staging at the end of the neoadjuvant chemotherapy was performed in order to evaluate the tumoral response. The imaging studies confirmed the absence of distant tumoral progression as well as the partial response to chemotherapy - partial regression of the tumor in all cases. However, in all cases a degree of vascular invasion was still present, so vascular resection was needed in all eight cases. Among patients submitted to neoadjuvant chemotherapy followed by resection, the surgical procedure was performed after a median interval of 45 days after ending the oncological systemic treatment. Portal vein invasion was still present in all cases but significantly diminished under chemotherapy so the patients were considered eligible for resection with curative intent. Intraoperatively, the persistence of the superior mesenteric artery invasion was encountered in two cases; however, due to the fact that arterial invasion was limited, resection with curative intent was performed in both cases.

When it comes to the type of surgery, it consisted of standard pancreatoduodenectomy in nine cases, pylorous preserving pancreatoduodenectomy in three cases and total pancreatectomy in the remaining three cases. Clinicopathological data of the resected patients are shown in Table I.

As for the completeness of resection, in all cases an R0 resection was demonstrated by the histopathological studies. Moreover, in nine of the 15 cases the tumoral involvement of all the portal vein layers was demonstrated by the microscopic analysis, while in two of the four cases the arterial microscopic invasion was also found.

Regarding postoperative outcomes, five of the 15 patients developed postoperative pancreatic surgery-related complications which consisted of the development of pancreatic leaks in three cases and postoperative hemorrhage in two cases. Details of the patients who developed postoperative complications are shown in Table II.

As shown in Table II, the postoperative complication rate was $33 \%$ while the postoperative mortality rate was $20 \%$.

\section{Discussion}

Despite the recent advantages reported in the field of medical oncology, pancreatic tumors are still associated with poor long-term outcomes, especially in cases diagnosed with pancreatic adenocarcinomas (12, 20-22). At the moment, pancreatic cancer represents the fourth cause of cancerrelated death in developed countries worldwide and is expected to become the second cause of cancer-related deaths by the year of 2030 (23). 
Table I. Clinicopathological data of the resected patients.

\begin{tabular}{|c|c|c|}
\hline Variable & Per primam resection ( 8 cases) & $\begin{array}{l}\text { Neoadjuvant chemotherapy } \\
\text { followed by resection ( } 7 \text { cases) }\end{array}$ \\
\hline Age (years, median) & 43 years ( $38-53$ years) & 45 years ( $41-56$ years) \\
\hline \multicolumn{3}{|l|}{ Gender } \\
\hline Male & 5 cases & 4 cases \\
\hline Female & 3 cases & 3 cases \\
\hline \multicolumn{3}{|l|}{ Type of surgery: } \\
\hline Standard pancreatoduodenectomy & 5 cases & 4 cases \\
\hline Pylorous preserving pancreatoduodenectomy & 2 cases & 1 case \\
\hline Total pancreatectomy & 1 case & 2 cases \\
\hline \multicolumn{3}{|l|}{ Venous resection } \\
\hline Portal vein resection & 8 cases & 7 cases \\
\hline \multicolumn{3}{|l|}{ Arterial resection } \\
\hline Superior mesenteric artery resection & 2 cases & 2 cases \\
\hline Length of surgery (minutes, median) & 280 minutes (240-360 minutes) & 320 minutes (260-400 minutes) \\
\hline Hospital stay (days, median) & 10 days (7-31 days) & 12 days (8-29 days) \\
\hline \multicolumn{3}{|c|}{ Postoperative pancreatic surgery related complications: } \\
\hline Pancreatic leaks & 1 & 2 \\
\hline Postoperative hemorrhage & 1 & 1 \\
\hline Postoperative death & 1 & 2 \\
\hline
\end{tabular}

Although initially it was considered that the presence of vascular invasion was a sign of an unresectable lesion, this myth was destroyed once it was demonstrated that pancreatic resections en bloc with vascular resections can be safely performed and the long-term outcomes are similar to cases submitted to pancreatic resections in the absence of vascular resections. In the meantime, the concept of downstaging the lesion by neoadjuvant chemotherapy alone or in association with radiotherapy also increased the number of cases who benefited from radical surgical procedures $(24,25)$.

Therefore, attention has been focused on improving the surgical techniques in order to achieve the resectability of a higher number of patients diagnosed with locally advanced pancreatic lesions. This fact has been achieved by improving the surgical techniques, the perioperative outcomes as well as the preoperative neoadjuvant protocol.

In this respect, a significant benefit was achieved once the FOLFIRINOX protocol was introduced. This protocol consists of systemic administration of 5-fluorouracil, leucovorin, irinotecan and oxaliplatin and seems to increase the rates of resectability and, in the meantime to decrease the rates of lymph node positivity, perineural invasion and postoperative morbidity $(26,27)$.

When it comes to the therapeutic decision in borderline resectable lesions of the pancreatic head, they might consist of per primam surgical resection or chemotherapy followed by resection. While in cases in which only venous resection is diagnosed preoperatively surgery with curative intent consisting of pancreatic and venous resection and reconstruction might be considered, cases presenting both arterial and venous invasion can be considered as candidates for per primam surgery or for neoadjuvant chemotherapy followed by surgery. However, if arterial invasion is not suspected preoperatively and is discovered only at the time of surgery the decision should be taken according to the local anatomy and to the experience of the surgical team. In such cases, no clear recommendation is given, and the options of choice are to continue the procedure by performing an extended resection involving the arterial invaded segment or to postpone surgery, not resect the tumor and to submit the patient to neoadjuvant chemotherapy followed by consecutive surgical re-exploration $(3,28,29)$.

In regards to the surgical options of venous reconstruction after portal vein resections, four types of reconstruction have been reported so far; the first type is addressed for tangential, limited invasion and consists of tangential resection followed by direct suturing, the second situation is represented by the same type of resection followed by venous reconstruction by using a patch, the third situation is represented by a circumferential resection followed by direct anastomosis while the fourth situation consists of circumferential resection and graft interposition $(3,30,31)$. In our cohort, five patients were submitted to the first type of reconstruction, seven patients were submitted to the third type of reconstruction and three cases were submitted to the fourth type.

As for arterial involvement, tumoral infiltration of these structures should be considered as a sign of an extremely aggressive lesion and the decision of performing an arterial resection should be tailored to each patient. The decision of performing this type of resection should be taken based on 
Table II. Postoperative complications after pancreatic resections.

\begin{tabular}{|c|c|c|c|c|c|c|c|}
\hline Patient & Age & $\begin{array}{l}\text { Neoadjuvant } \\
\text { chemotherapy }\end{array}$ & $\begin{array}{l}\text { Type of } \\
\text { surgery }\end{array}$ & $\begin{array}{c}\text { Clavien - } \\
\text { Dindo grade }\end{array}$ & $\begin{array}{c}\text { Type of } \\
\text { complication }\end{array}$ & Management & $\begin{array}{c}\text { Short term } \\
\text { outcomes }\end{array}$ \\
\hline 1 & 45 & Yes & $\begin{array}{l}\text { Standard pancreatoduodenectomy, } \\
\text { portal vein resection } \\
\text { and reconstruction }\end{array}$ & 3 & $\begin{array}{c}\text { Pancreatic } \\
\text { leak }\end{array}$ & $\begin{array}{l}\text { Conservative } \\
\text { management, } \\
\text { drain placement }\end{array}$ & $\begin{array}{l}\text { Discharged } \\
\text { in the 29th } \\
\text { postoperative day }\end{array}$ \\
\hline 2 & 48 & No & $\begin{array}{l}\text { Standard pancreatoduodenectomy, } \\
\text { portal vein resection and } \\
\text { reconstruction, superior mesenteric } \\
\text { artery resection and reinsertion } \\
\text { in the abdominal aorta }\end{array}$ & 5 & $\begin{array}{l}\text { Postoperative } \\
\text { hemorrhage }\end{array}$ & $\begin{array}{c}\text { Re-operation } \\
\text { in day } 3- \\
\text { hemoperitoneum }\end{array}$ & $\begin{array}{l}\text { Died in the } \\
\text { fourth } \\
\text { post-reoperation } \\
\text { day }\end{array}$ \\
\hline 3 & 44 & Yes & $\begin{array}{l}\text { Standard pancreatoduodenectomy, } \\
\text { portal vein resection and } \\
\text { reconstruction, superior } \\
\text { mesenteric artery resection } \\
\text { and reimplantation }\end{array}$ & 5 & $\begin{array}{c}\text { Pancreatic } \\
\text { leak }\end{array}$ & $\begin{array}{l}\text { Reoperation, } \\
\text { totalisation of } \\
\text { pancreatectomy, } \\
\text { multiple organ } \\
\text { dysfunction, death }\end{array}$ & $\begin{array}{l}\text { Death in the } \\
18 \text { th } \\
\text { postoperative } \\
\text { day }\end{array}$ \\
\hline 4 & 51 & No & $\begin{array}{l}\text { Pylorus preserving } \\
\text { pancreaticoduodenectomy, } \\
\text { portal vein resection } \\
\text { and reconstruction }\end{array}$ & 3 & $\begin{array}{c}\text { Pancreatic } \\
\text { leak }\end{array}$ & $\begin{array}{l}\text { Conservative } \\
\text { management }\end{array}$ & $\begin{array}{l}\text { Discharged in } \\
\text { the } 31 \text { th } \\
\text { postoperative day }\end{array}$ \\
\hline 5 & 56 & Yes & $\begin{array}{l}\text { Standard pancreatoduodenectomy, } \\
\text { portal vein resection } \\
\text { and reconstruction }\end{array}$ & 5 & $\begin{array}{l}\text { Postoperative } \\
\text { hemorrhage }\end{array}$ & $\begin{array}{c}\text { Reoperation, } \\
\text { multiple organ } \\
\text { dysfunction, death }\end{array}$ & $\begin{array}{l}\text { Death in the } \\
\text { eight } \\
\text { postoperative day }\end{array}$ \\
\hline
\end{tabular}

the extent of the arterial involvement as well as on the clinical and biological status of the patient (3). In cases in which the preoperative investigations do not show the presence of an arterial invasion but indirect signs pointing to this invasion might be identified (related to the dimensions and location of the tumor) most authors propose performing an artery first approach in order to avoid reaching a point of no return situation during the surgical procedure (32-34).

As for the role of neoadjuvant chemotherapy, it has been widely demonstrated that no neoadjuvant chemotherapy should be performed in cases presenting borderline resectable lesions with venous invasion. In such cases, the International Study Group of Pancreatic Surgery decided for up front resection followed by adjuvant chemotherapy (35). In the meantime, in cases presenting clear data suggesting the presence of arterial invasion, neoadjuvant chemotherapy might be beneficial in order to diminish the tumoral volume and to provide the chance to perform a radical procedure. Moreover, the response to neoadjuvant chemotherapy can give certain information in regard to the biology of the tumor, cases presenting an aggressive biology of the lesion reporting more often a poor response to chemotherapy (35).

\section{Conclusion}

Vascular resections might increase the rates of radical surgery in patients with pancreatic head tumors and vascular invasion. However, the decision of performing up front surgery or neoadjuvant chemotherapy followed by surgery should be taken in regard to the extent of the tumor and the invasion of the venous and arterial structures. While in cases presenting limited portal vein resection surgery should be routinely performed, in cases in which arterial invasion is encountered, a tailored approach to each case should be proposed.

\section{Conflicts of Interest}

There are no conflicts of interest to declare regarding this study.

\section{Acknowledgements}

This work was supported by the project entitled "Multidisciplinary Consortium for Supporting the Research Skills in Diagnosing, Treating and Identifying Predictive Factors of Malignant Gynecologic Disorders", project number PN-III-P1-1.2-PCCDI2017-0833.

\section{Authors' Contributions}

$\mathrm{NB}, \mathrm{VB}, \mathrm{IB}$ - performed surgery; AC -conducted the oncological treatment; IB, MB, SD - prepared the manuscript; IB - revised the final draft of the manuscript.

\section{References}

1 Siegel RL, Miller KD and Jemal A: Cancer statistics, 2015. CA Cancer J Clin 65: 5-29, 2015. PMID: 25559415. DOI: 10.3322/ caac. 21254

2 Hackert T and Buchler MW: Pancreatic cancer: advances in treatment, results and limitations. Dig Dis 31: 51-56, 2013. PMID: 23797123. DOI: 10.1159/000347178 
3 Hackert T, Ulrich A and Buchler MW: Borderline resectable pancreatic cancer. Cancer Lett 375: 231-237, 2016. PMID: 26970276. DOI: 10.1016/j.canlet.2016.02.039

4 Brasoveanu V, Anghel C, Barbu I, Pautov M, Ionescu MI, Motthor M, Balescu I, Dima $S$ and Bacalbasa N: Pancreatoduodenectomy en bloc with portal and superior mesenteric artery resection - a case report and literature review. Anticancer Res 35: 1613-1618, 2015. PMID: 25750318.

5 Bacalbasa N, Balescu I, Vilcu M, Brasoveanu V, Tomescu D, Dima S, Suciu I, Suciu N, Bodog A and Brezean I: Distal pancreatectomy en bloc with splenectomy as part of tertiary cytoreduction for relapsed ovarian cancer Proceedings of the 4th congress of the romanian society for minimal invasive surgery in ginecology/annual days of the national institute for mother and child health Alessandrescu-Rusescu, ISI Proceedings Volume, 29-32, 2019.

6 Brezean I, Aldoescu S, Catrina E, Fetche N, Marin I and Pacescu E: Gallstone ileus: analysis of eight cases and review of the literature. Chirurgia 105: 355-359, 2010, PMID: 20726301.

7 Bacalbasa N, Balescu I, Tanase A, Brezean I, Vilcu M and Brasoveanu V: Successful resection of a non-functional paraganglioma with celiac trunk invasion followed by common hepatic artery reimplantation - A case report and literature review. In Vivo 32: 911-914, 2018, PMID: 29936479. DOI: 10.21873/invivo. 11328

8 Bacalbasa N, Brezean I, Anghel C, Barbu I, Pautov M, Balescu $\mathrm{I}$ and Brasoveanu V: Management of a fulminant upper gastrointestinal bleeding exteriorized through hemobilia due to arteriobiliary fistula between the common bile duct and a right hepatic artery aneurysm - a case report. In Vivo 31: 983-989, 2017. PMID: 28882970

9 Bacalbasa N, Brezean I, Anghel C, Barbu I, Pautov M, Balescu I and Brasoveanu V: Successful resection and vascular ligation of a large hepatic artery aneurysm - a case report and literature review. In Vivo 31: 979-982, 2017. PMID: 28882969.

10 Brasoveanu V, Ionescu MI, Grigorie R, Mihaila M, Bacalbasa N, Dumitru R, Herlea V, Iorgescu A, Tomescu D and Popescu I: Living donor liver transplantation for unresectable liver adenomatosis associated with congenital absence of portal vein: a case report and literature review. Am J Case Rep 16: 637-644, 2015. PMID: 26386552. DOI: 10.12659/AJCR.895235

11 Bacalbasa N, Balescu I, Tanase A, Pautov M, Brezean I, Vilcu $\mathrm{M}$ and Brasoveanu V: Spleno-pancreatectomy en bloc with parcelar gastrectomy for splenic artery aneurysm - a case report and literature review. In Vivo 32: 915-919, 2018. PMID: 29936480. DOI: 10.21873 /invivo.11329

12 Dima SO, Dumitrascu T, Pechianu C, Grigorie RT, Brasoveanu V, Sorop A, Lupescu I, Purnichescu-Purtan R, Croitoru A, Bacalbasa N, Tanase A, Tomescu DR, Herlea V and Popescu I: Prognostic factors in patients with surgical resection of pancreatic neuroendocrine tumours. Acta Endocrinol 14: 389393, 2018. PMID: 31149288. DOI: 10.4183/aeb.2018.389

13 Rhim AD, Mirek ET, Aiello NM, Maitra A, Bailey JM, McAllister F, Reichert M, Beatty GL, Rustgi AK, Vonderheide RH, Leach SD and Stanger BZ: EMT and dissemination precede pancreatic tumor formation. Cell 148: 349-361, 2012. PMID: 22265420. DOI: 10.1016/j.cell.2011.11.025

14 Yachida S, Jones S, Bozic I, Antal T, Leary R, Fu B, Kamiyama M, Hruban RH, Eshleman JR, Nowak MA, Velculescu VE, Kinzler KW, Vogelstein B and Iacobuzio-Donahue CA: Distant metastasis occurs late during the genetic evolution of pancreatic cancer. Nature 467: 1114-1117, 2010. PMID: 20981102. DOI: 10.1038/nature09515

15 Varadhachary GR, Tamm EP, Abbruzzese JL, Xiong HQ, Crane CH, Wang H, Lee JE, Pisters PW, Evans DB and Wolff RA: Borderline resectable pancreatic cancer: definitions, management, and role of preoperative therapy. Ann Surg Oncol 13: 1035-1046, 2006. PMID: 16865597. DOI: 10.1245/ASO.2006.08.011

16 Tempero MA, Malafa MP, Al Hawary M, Asbun H, Bain A, Behrman SW, Benson AB, III, Binder E, Cardin DB, Cha C, Chiorean EG, Chung V, Czito B, Dillhoff M, Dotan E, Ferrone CR, Hardacre J, Hawkins WG, Herman J, Ko AH, Komanduri S, Koong A, LoConte N, Lowy AM, Moravek C, Nakakura EK, O'Reilly EM, Obando J, Reddy S, Scaife C, Thayer S, Weekes CD, Wolff RA, Wolpin BM, Burns J and Darlow S: Pancreatic Adenocarcinoma, Version 2 2017, NCCN Clinical Practice Guidelines in Oncology. J Natl Compr Canc Netw 15: 10281061, 2017. PMID: 28784865. DOI: 10.6004/jnccn.2017.0131

17 Tsai S, Christians KK, Ritch PS, George B, Khan AH, Erickson $\mathrm{B}$ and Evans DB: Multimodality therapy in patients with borderline resectable or locally advanced pancreatic cancer: importance of locoregional therapies for a systemic disease. $\mathbf{J}$ Oncol Pract 12: 915-923, 2016. PMID: 27858562. DOI: 10.1200/JOP.2016.016162

18 Clavien PA, Barkun J, de Oliveira ML, Vauthey JN, Dindo D, Schulick RD, de Santibanes E, Pekolj J, Slankamenac K, Bassi C, Graf R, Vonlanthen R, Padbury R, Cameron JL and Makuuchi M: The Clavien-Dindo classification of surgical complications: five-year experience. Ann Surg 250: 187-196, 2009. PMID: 19638912. DOI: $10.1097 /$ SLA.0b013e3181b13ca2

19 Dusch N, Lietzmann A, Barthels F, Niedergethmann M, Ruckert F and Wilhelm TJ: International Study Group of Pancreatic Surgery Definitions for Postpancreatectomy Complications: Applicability at a High-Volume Center. Scand J Surg 106: 216223, 2017. PMID: 28376656. DOI: 10.1177/1457496916680944

20 Fazio N, Martini JF, Croitoru AE, Schenker M, Li S, Rosbrook B, Fernandez K, Tomasek J, Thiis-Evensen E, Kulke M and Raymond E: Pharmacogenomic analyses of sunitinib in patients with pancreatic neuroendocrine tumors. Future Oncol 15: 19972007, 2019. PMID: 31084373. DOI: 10.2217/fon-2018-0934

21 Croitoru A, Gramaticu I, Dinu I, Gheorghe L, Alexandrescu S, Buica F, Luca I, Becheanu G, Herlea V, Simionov I, Hrehoret D, Lupescu I, Popescu I and Diculescu M: Fluoropyrimidines plus cisplatin versus gemcitabine/gemcitabine plus cisplatin in locally advanced and metastatic biliary tract carcinoma - a retrospective study. J Gastrointestin Liver Dis 21: 277-284, 2012. PMID: 23012669.

22 Vrdoljak E, Wojtukiewicz MZ, Pienkowski T, Bodoky G, Berzinec P, Finek J, Todorovic V, Borojevic N and Croitoru A: Cancer epidemiology in Central, South and Eastern European countries. Croat Med J 52: 478-487, 2011. PMID: 21853542. DOI: $10.3325 / \mathrm{cmj} .2011 .52 .478$

23 Rahib L, Smith BD, Aizenberg R, Rosenzweig AB, Fleshman $\mathrm{JM}$ and Matrisian LM: Projecting cancer incidence and deaths to 2030: the unexpected burden of thyroid, liver, and pancreas cancers in the United States. Cancer Res 74: 2913-2921, 2014. PMID: 24840647. DOI: 10.1158/0008-5472.CAN-14-0155

24 Fortner JG: Regional pancreatectomy for cancer of the pancreas, ampulla, and other related sites. Tumor staging and results. Ann Surg 199: 418-425, 1984. PMID: 6712317. DOI: 10.1097/0000 0658-198404000-00008 
25 Pilepich MV and Miller HH: Preoperative irradiation in carcinoma of the pancreas. Cancer 46: 1945-1949, 1980. PMID: 7427900. DOI: 10.1002/1097-0142(19801101)46:9<1945::aidcncr2820460908>3.0.co;2-x

26 Ferrone CR, Marchegiani G, Hong TS, Ryan DP, Deshpande V, McDonnell EI, Sabbatino F, Santos DD, Allen JN, Blaszkowsky LS, Clark JW, Faris JE, Goyal L, Kwak EL, Murphy JE, Ting DT, Wo JY, Zhu AX, Warshaw AL, Lillemoe KD and Fernandez-del Castillo C: Radiological and surgical implications of neoadjuvant treatment with FOLFIRINOX for locally advanced and borderline resectable pancreatic cancer. Ann Surg 261: 12-17, 2015. PMID: 25599322. DOI: $10.1097 /$ SLA.0000000000000867

27 Tang K, Lu W, Qin W and Wu Y: Neoadjuvant therapy for patients with borderline resectable pancreatic cancer: A systematic review and meta-analysis of response and resection percentages. Pancreatology 16: 28-37, 2016. PMID: 26687001. DOI: $10.1016 /$ j.pan.2015.11.007

28 Siriwardana HP and Siriwardena AK: Systematic review of outcome of synchronous portal-superior mesenteric vein resection during pancreatectomy for cancer. Br J Surg 93: 662673, 2006. PMID: 16703621. DOI: 10.1002/bjs.5368

29 Zhou Y, Zhang Z, Liu Y, Li B and Xu D: Pancreatectomy combined with superior mesenteric vein-portal vein resection for pancreatic cancer: a meta-analysis. World J Surg 36: 884-891, 2012. PMID: 22350478. DOI: 10.1007/s00268-012-1461-Z

30 Tseng JF, Raut CP, Lee JE, Pisters PW, Vauthey JN, Abdalla EK, Gomez HF, Sun CC, Crane CH, Wolff RA and Evans DB: Pancreaticoduodenectomy with vascular resection: margin status and survival duration. J Gastrointest Surg 8: 935-949, 2004. PMID: 15585381. DOI: 10.1016/j.gassur.2004.09.046

31 Del Chiaro M, Segersvard R, Rangelova E, Coppola A, Scandavini CM, Ansorge C, Verbeke C and Blomberg J: CattellBraasch maneuver combined with artery-first approach for superior mesenteric-portal vein resection during pancreatectomy. J Gastrointest Surg 19: 2264-2268, 2015. PMID: 26423804. DOI: $10.1007 / \mathrm{s} 11605-015-2958-1$
32 Weitz J, Rahbari N, Koch M and Buchler MW: The "artery first" approach for resection of pancreatic head cancer. J Am Coll Surg 210: e1-e4, 2010. PMID: 20113929. DOI: 10.1016/j.jamcoll surg.2009.10.019

33 Sanjay P, Takaori K, Govil S, Shrikhande SV and Windsor JA: 'Artery-first' approaches to pancreatoduodenectomy. Br J Surg 99: 1027-1035, 2012. PMID: 22569924. DOI: 10.1002/bjs.8763

34 Inoue Y, Saiura A, Yoshioka R, Ono Y, Takahashi M, Arita J, Takahashi $\mathrm{Y}$ and Koga R: Pancreatoduodenectomy with systematic mesopancreas dissection using a supracolic anterior artery-first approach. Ann Surg 262: 1092-1101, 2015. PMID: 25587814. DOI: $10.1097 /$ SLA.0000000000001065

35 Bockhorn M, Uzunoglu FG, Adham M, Imrie C, Milicevic M, Sandberg AA, Asbun HJ, Bassi C, Buchler M, Charnley RM, Conlon K, Cruz LF, Dervenis C, Fingerhutt A, Friess H, Gouma DJ, Hartwig W, Lillemoe KD, Montorsi M, Neoptolemos JP, Shrikhande SV, Takaori K, Traverso W, Vashist YK, Vollmer C, Yeo CJ and Izbicki JR: Borderline resectable pancreatic cancer: a consensus statement by the International Study Group of Pancreatic Surgery (ISGPS). Surgery 155: 977-988, 2014. PMID: 24856119. DOI: 10.1016/j.surg.2014.02.001

Received September 6, 2019

Revised September 20, 2019

Accepted September 23, 2019 